compound, which may be called cysteinethiosulphonic acid : $R-\mathrm{S}-\mathrm{S}-\mathrm{SO}_{3} \mathrm{H}$. Its formation can be explained by the reaction :

$R-\mathrm{S}-\mathrm{S}-R+-\mathrm{S}-\mathrm{SO}_{3}^{-} \rightarrow R-\mathrm{S}-\mathrm{S}-\mathrm{SO}_{3}^{-}+R \mathrm{~S}^{-}$

This supposition is supported by the fact that a warmed solution of cysteine and thiosulphate tested chromatographically also gives two spots located in exactly the same positions as those described above. The second reason is that a compound with $R_{F}$ value $0.08-0.1$ is formed during the oxidation of a cysteine and thiosulphate mixture with iodine. In this case there are three possible parallel reactions :

$$
\begin{aligned}
& 2 R-\mathrm{SH}+\mathrm{I}_{2} \rightarrow R-\mathrm{S}-\mathrm{S}-R+2 \mathrm{H}^{+}+2 \mathrm{I}^{-} \\
& 2-\mathrm{S}-\mathrm{SO}_{3}^{-}+\mathrm{I}_{2} \rightarrow-\mathrm{O}_{3} \mathrm{~S}-\mathrm{S}-\mathrm{S}-\mathrm{SO}_{3}^{-}+2 \mathrm{I}^{-} \\
& -\mathrm{S}-\mathrm{SO}_{3}^{-}+R-\mathrm{SH}+\mathrm{I}_{2} \rightarrow R-\mathrm{S}-\mathrm{S}-\mathrm{SO}_{3}^{-}+ \\
& \mathrm{H}^{+}+2 \mathrm{I}^{-}
\end{aligned}
$$

The third reaction produces cysteinethiosulphonic acid, which can be identified chromatographically.

(3) The reaction of cysteine with tetrathionate is connected with the facts described above. When solutions of these compounds ( $\mathrm{m} M: \mathrm{m} M$ ) were mixed together a white precipitate was quickly formed, which was identified as cystine, but other products are also formed. Curiously enough, the chromatograms of the solution revealed the existence of three spots located near one another. The two lower spots corresponded to those of eysteinesulphonic acid and cysteinethiosulphonic acid, the third presumably belongs to a compound which may be called cysteinedithiosulphonic acid, $R-\mathrm{S}-\mathrm{S}-\mathrm{S}-\mathrm{SO}_{3} \mathrm{H}$. The reaction which led to the formation of this acid may be formulated :

$$
\begin{array}{r}
R-\mathrm{SH}+-\mathrm{O}_{3} \mathrm{~S}-\mathrm{S}-\mathrm{S}-\mathrm{SO}_{3}^{-} \longrightarrow R-\mathrm{S}-\mathrm{S}-\mathrm{S}-\mathrm{SO}_{3}^{-} \\
+\mathrm{HSO}_{3}^{-}
\end{array}
$$

If the formulations of the reactions described above are correct, a way is opened for the synthesis of a new class of compounds which may be called cysteinepolythiosulphonic acids. Further studies are in progress.

Tapeusz W. Szczepkowski

Department of Physiological Chemistry, Medical Academy, Cracow.

${ }^{1}$ Clarke, H. T., J. Biot. Chem., 97, 235 (1932).

\section{Inhibition of Cholinesterase Hydrolysis of Dihydromurexine by Lysergic Acid Diethylamide and its 2-Bromo Derivative : a Selective Relationship}

Previous investigators have shown that human plasma cholinesterase is strongly inhibited by both lysergic acid diethylamide (LSD) and its 2-bromo derivative (BOL). The cholinesterases of other species were less sensitive to the effects of both these substances $^{1-3}$. Recent reports described certain newer choline esters, namely, imidazoleacrylylcholine ${ }^{45}$ (murexine), imidazoleacetylcholine ${ }^{6}$ and imidazolepropionylcholine (dihydromurexine) which are hydrolysed most readily by human plasma cholinesterase ${ }^{7-10}$. These observations have led us to evaluate the possible relationship between cholinesterase inhibition by lysergic acid diethylamide and BOL and cholinesteraso hydrolysis of dihydromurexine. DihydroTable 1. HYDROLYSIS OF BUTYRYLCHOLINE AND IMIDAZOLEPRO-
PIONYLCHOLINE BY SERA OF SEVERAL SPECIES AND THE INHIBTTORY EFFECTS OF LYSERGIC ACID DIETHYLAMIDE

\begin{tabular}{|c|c|c|c|c|}
\hline Substrate & \multicolumn{2}{|c|}{ Butyrylcholine } & \multicolumn{2}{|c|}{ Dihydromurexine } \\
\hline Species $\quad$ Inhibitor & -LSD & $+\mathrm{LSD}$ & $-\operatorname{LSD}$ & $+\mathrm{LSO}$ \\
\hline $\begin{array}{l}\text { Cat } \\
\text { Dog } \\
\text { Guinea pig } \\
\text { Mouse } \\
\text { Human }\end{array}$ & $\begin{array}{l}H \\
H \\
H \\
H \\
H \\
H\end{array}$ & $\begin{array}{l}H \\
H \\
I I \\
I \\
I\end{array}$ & $\begin{array}{l}\bar{Z} \\
\bar{H} \\
H\end{array}$ & $\begin{array}{l}- \\
\bar{I} \\
I\end{array}$ \\
\hline
\end{tabular}
buffer of $1: 10$ dilution of serum; 0.5 or $1 \mathrm{ml}$. of $0.1 M$ phosphate $8 \times 10^{-6} M: 0.5 \mathrm{ml}$. of inhibitor to give a final concentration of equivalent amount of butyrylcholine $(800 \mu \mathrm{gm} . / \mathrm{ml}$.) or $0.5 \mathrm{ml}$. of incubation time, $10 \mathrm{~min}$. dihydromurexine; temperature, $37^{\circ} \mathrm{C}$.; measured by Hestrin's method (ref. 11)

$H, 90-100$ per cent hydrolysis of substrate; $I, 90-100$ per cent inhibition ; --, no hydrolysis of substrate.

murexine was chosen as the model substrate because it is the most active of the three esters.

Table I indicates that though all the sera tested hydrolysed butyrylcholine, only mouse and human sera hydrolysed dihydromurexine under the conditions of these experiments. Moreover, only mouse and human serum cholinesterases were inhibited by lysergic acid diethylamide. Similar findings were obtained employing BOL as the inhibitor.

Further experiments have shown that both mouse and rat brain homogenates hydrolyse butyrylcholine. However, the pseudocholinesterase of mouse brain differed from that of rat brain in two respects: (1) mouse brain cholinesterase catalysed the hydrolysis of dihydromurexine, and (2) this enzyme was strongly inhibited by lysergic acid diethylamide or BOL. Rat brain cholinesterase did not display either of these properties. Thus, in all cases tested so far, a potent inhibition of cholinesterase by lysergic acid diethylamide or BOL was observed only when the enzyme was capable of hydrolysing dihydromurexine.

These results suggest that a specific enzymesubstrate relationship (ability of some cholinesterases to hydrolyse dihydromurexine) is the basis for the selectivity displayed by lysergic acid diethylamide and BOL towards various cholinesterases. The identification and evaluation of other choline ester's may aid in clarifying this observation.

\section{I. A. TABACHNICK \\ M. E. GRELIS}

Department of Pharmacology,

Scientific Research Division,

Schering Corporation,

Bloomfield, New Jersey. July 21 .

${ }^{1}$ Thompson, R. H. S., Tickner, A., and Webster, G. R., Brit. I. Pharmacol., 10, 61 (1955).

${ }^{2}$ Zehnder, V. K., and Cerletti, A., Helv. Physiol. Pharmacol. Acta, 14, 264 (1956)

${ }^{3}$ Fried, G. H., and Antopol, W., J. App. Physiol., 11, 25 (1957).

- Erspamer, V., and Benati, O., Science, 11\%, 161 (1953).

5 Keyl, M. J., Michaelson, I. A., and Whittaker, V. P., J. Physiol., 139, 434 (1957).

${ }^{6}$ Grunert, G., and Kewitz, H., Naturwiss., 42, 628 (1955)

7 Foldes, F. F., Brdös, E. G., Baart, N., and Shanor, S. P., Proc. Soc. Exp. Biol. N.Y., 94, 500 (1957).

Grelis, M. E., and Tabachnick, I. I. A., Brit. J. Pharmacol., 12, 320) (1957).

${ }^{9}$ Keyl, M. J., and Whittaker, V. P., Brit. J. Pharmacol., 13, 103 (1958). ${ }^{10}$ Tabachnick, I. I. A., Roth, F. E., Mershon, J. S., Rubin, A. A., ${ }^{1_{1}}$ Hestrin, S., J. Biol. Chem., 180, 249 (1949). 